\title{
Swallowing disorders after treatment for head and neck cancer
}

\author{
Martina Pezdirec ${ }^{1}$, Primoz Strojan², Irena Hocevar Boltezar ${ }^{1,3}$ \\ ${ }^{1}$ Faculty of Medicine, University of Ljubljana, Ljubljana, Slovenia \\ ${ }^{2}$ Institute of Oncology, Ljubljana, Slovenia \\ ${ }^{3}$ University Department of Otorhinolaryngology and Cervicofacial Surgery, University Medical Center, Ljubljana, Slovenia
}

Radiol Oncol 2019; 53(2): 225-230.

Received 04 February 2019

Accepted 23 April 2019

Correspondence to: Irena Hočevar Boltežar, M.D., Ph.D., University Department of Otorhinolaryngology and Cervicofacial Surgery, University Medical Centre, Zaloška cesta 2, 1000 Ljubljana, Slovenia. Phone: +386 41958 336; Fax: +386 152241 08; E-mail: boltezar.irena@gmail.com or irena.hocevar-boltezar@mf.uni-lj.si

Disclosure: No potential conflicts of interest were disclosed.

Background. Dysphagia is a common consequence of treatment for head and neck cancer (HNC). The purpose of the study was to evaluate the prevalence of dysphagia in a group of patients treated for HNC in Slovenia, and to identify factors contributing to the development of dysphagia.

Patients and methods. One-hundred-nine consecutive patients treated for HNC at two tertiary centers were recruited during their follow-up visits. They fulfilled EORTC QLQ-H\&N35 and "Swallowing Disorders after Head and Neck Cancer Treatment questionnaire" questionnaires. Patients with dysphagia were compared to those without it.

Results. Problems with swallowing were identified in $41.3 \%$ of the patients. Dysphagia affected their social life (in $75.6 \%$ ), especially eating in public (in $80 \%$ ). Dysphagia was found the most often in the patients with oral cavity and/ or oropharyngeal cancer (in 57.6\%) and in those treated less than 2 years ago ( $p=0.014$ ). In univariate analysis, a significant relationship was observed between dysphagia prevalence and some of the consequences of anti-cancer treatment (impaired mouth opening, sticky saliva, loss of smell, impaired taste, oral and throat pain, persistent cough, and hoarseness), radiotherapy ( $p=0.003)$, and symptoms of gastroesophageal reflux $(p=0.027)$. After multiple regression modelling only persistent cough remained.

Conclusions. In order to improve swallowing abilities and, consequently, quality of life of the patients with HNC a systematic rehabilitation of swallowing should be organized. A special emphasis should be given to gastroesophageal reflux treatment before, during and after therapy for HNC.

Key words: head and neck cancer; swallowing disorders; symptoms; questionnaire; quality of life

\section{Introduction}

In 2015, head and neck cancer (HNC) represented $3.5 \%$ of all cancer cases in Slovenia. It was the $7^{\text {th }}$ most common type of cancer in the population and with the share of $5.2 \%$ the $5^{\text {th }}$ most common cancer in males. Among 459 new HNC cases in Slovenia in 2015, there were 144 oral cavity primaries, 122 oropharyngeal, 70 hypopharyngeal, and 90 laryngeal primary tumors. Locally advanced disease stages (UICC TNM stages III or IVA-B) were diagnosed in $32 \%, 92 \%, 90 \%$ and $53 \%$ of patients with oral cavi- ty, oropharyngeal, hypopharyngeal, and laryngeal primaries, respectively. ${ }^{1}$

Due to its invasive growth with destruction of neighboring anatomical structures, HNC has an adverse effect on important functions, including swallowing, breathing, coughing and speech. Thus, it can profoundly influence quality of life of the patient. Treatment of the tumor may significantly deteriorate these functions. Treatment modalities, including surgery, irradiation and systemic therapy, either alone or combined, can result in tissue defects, excessive scarring, and changed anatomi- 
cal setting and function of the involved organs..$^{2-6}$ The treatment options in late sequelae of different therapies are limited and of variable benefit. ${ }^{7}$

Dysphagia is an important cause of malnutrition, dehydration, weight loss, chronic aspiration and aspiration pneumonia. All these complications can lead to not only serious health issues and even death, but may also result in depression and social isolation..$^{8-15}$ In addition, late dysphagia, even of a mild grade, is one of the most important factors adversely influencing quality of life of HNC patients, with feeding-tube dependency having the most negative impact. ${ }^{9}$

In the present cross-sectional study, we investigated the most common dysphagia-related factors and problems in a group of survivors who were treated for HNC in the last decade at two tertiary centers. The primary aim was to identify factors that participate to the development of dysphagia in studied cohort of HNC patients.

\section{Patients and methods}

\section{Patient's selection}

The study cohort consisted of 109 patients who have been successfully treated for HNC in the past decade with either primary surgery or (chemo) radiotherapy. The consecutive patients who came for their regular follow-up visits to the Outpatient Clinics of the Institute of Oncology Ljubljana (IOL) or the University Department of Otorhinolaryngology and Cervicofacial Surgery (ORL), University Medical Center Ljubljana during the period October-December 2017 and were willing to participate were included in the study.

\section{Questionnaires}

The patients completed Slovenian translation of the EORTC QLQ-H\&N35 questionnaire, and the "Swallowing Disorders after Head and Neck Cancer Treatment" questionnaire. The first one evaluates the impact of head and neck cancer and its treatment on quality of patient's life. ${ }^{16}$ It comprises of 35 items, which can be condensed into seven multi-item and eleven single-item symptom scales. Only those 23 questions related to swallowing and to organs involved were considered for the further analyses. The second questionnaire was specifically designed for the purpose of present study to determine the patients' age, gender, details concerning cancer treatment, swallowing problems, and associated diseases that may be re- lated to dysphagia (i.e. gastroesophageal reflux, stroke, recurrent pneumonia). The patients were asked to complete both questionnaires at the clinic while waiting for scheduled follow-up visit. If purposely agreed, the detailed information on their disease was collected from their medical documentation (i.e. primary tumor site, TNM stage).

\section{Statistical analysis}

Data was analyzed with SPSS version 22 (SPSS Inc., Chicago; USA) software package. Depending on whether swallowing problems were consistently reported in both questionnaires, the patients were divided into two groups, i.e. dysphagia group (DG) and to those without swallowing problems $(\mathrm{OTH})$. Groups were compared by using the $\chi^{2}$-test for trend or Fischer's exact test, and the t-test. Only those parameters which were found related to dysphagia were included into the multiple regression model. Non-significant variables were removed using backward stepwise selection. The level of statistical significance was set at 0.05 and all statistical tests were two-sided.

The study was conducted according to the Helsinki declaration and was approved by the National Medical Ethics Committee of the Republic of Slovenia (No. 0120-204/2017-3). All patients included in the study signed an informed consent confirming their voluntary participation in the study and agreement with analysis of data for the study purposes.

\section{Results}

\section{Patients' characteristics}

The study group consisted of 109 patients: 50 patients were recruited at the $\mathrm{IO}$, and 59 patients at the ORL. Their age ranged from 43 to 91 years (mean 65.4 years, standard deviation [SD] 10.6 years). There were 31 female (43 to 91 years, mean 68 years, SD 12 years) and 78 male (46 to 87 years, mean 64.5 years, SD 10 years) patients with no significant difference in age profile between the two $(\mathrm{p}=0.141)$.

The primary tumor sites were paranasal sinuses, nasal cavity or nasopharynx in altogether 10 patients $(9.2 \%)$, oral cavity or oropharynx in 33 $(30.3 \%)$, hypopharynx or larynx in 51 (46.8\%), and neck metastasis of unknown primary tumor in 15 patients $(13.8 \%)$.

Twenty-two patients $(20.2 \%)$ were treated only with surgery, 10 patients $(9.2 \%)$ only with radio- 
therapy, and 16 patients (14.7\%) with concurrent chemoradiotherapy. In 41 patients (37.6\%) surgery was followed by radiotherapy, and in 20 patients (18.3\%) surgery was followed by chemoradiotherapy.

The time interval between treatment completion and inclusion into the study ranged from 0.2 to 10 years (mean 3.13 years, SD 2.84 years). Sixty patients (55\%) finished therapy less than 2 years ago, and in 49 patients $(45 \%)$ treatment was completed more than 2 years before.

\section{Results of the questionnaires}

All 109 patients fulfilled both questionnaires. Eleven patients $(10.1 \%)$ did not give their permission to obtain data on their cancer and its treatment from medical documentation.

According to pre-defined criteria, 45 patients $(41.3 \%)$ were found to experience various swallowing difficulties, both in a week before the interview (EORTC QLQ-H\&N35 questionnaire) and generally ("Swallowing Disorders after Head and Neck Cancer Treatment" questionnaire), and were sorted into the DG group. Other 64 patients (58.7\%) who did not report problems with swallowing at all or only at one questionnaire formed the OTH group.

Dysphagia was reported in $2(20 \%)$ patients treated for cancer of the nasal cavity, paranasal sinuses or nasopharynx, 19 (57.6\%) patients treated for cancer of the oral cavity or oropharynx, 20 $(39.2 \%)$ patients treated for cancer of the hypopharynx or larynx, and in $4(26.7 \%)$ patients treated for neck metastasis of unknown primary tumor.

Twenty-seven out of 45 patients (60\%) with dysphagia finished their treatment less than 2 years before the study and four patients $(8.9 \%)$ from the DG group were feeding-tube-dependent.

In DG, impaired swallowing of liquids, soft food, and solid food was reported in 25 (55.6\%), $26(57.8 \%)$, and 42 cases (93.3\%), respectively. Problems with sticking food in the oral cavity or pharynx, and cough during or immediately after swallowing were present in $32(71.1 \%)$, and 33 (73.3\%) patients, respectively.

Results of comparison of different clinical and swallowing-related parameters between the DG and OTH are shown in Table 1. Only the significant results are presented. In 11 patients who did not give their consent to collect details on their disease from the medical documentation, information on the primary tumor site as provided by the themselves was used. (Table 1).
TABLE 1. Comparison of the patients with dysphagia and the patients without dysphagia after head and neck treatment. Only the significant results are presented

\begin{tabular}{|c|c|c|c|}
\hline Parameter & $\begin{array}{l}\text { No Dysphagia } \\
\mathrm{N}=64\end{array}$ & $\begin{array}{l}\text { Dysphagia } \\
\mathrm{N}=45\end{array}$ & P-Value \\
\hline $\begin{array}{l}\text { Swallowing vs. non-swallowing area } \\
\text { Oral cavity, oropharynx, } \\
\text { hypopharynx, larynx ( } N=84) \\
\text { Nasal cavity, paranasal sinuses, } \\
\text { nasopharynx, metastases ( } N=25)\end{array}$ & $\begin{array}{l}45(70.3 \%) \\
19(29.7 \%)\end{array}$ & $\begin{array}{l}39(86.7 \%) \\
6(13.3 \%)\end{array}$ & 0.046 \\
\hline $\begin{array}{l}\text { TNM stage* } \\
\text { Stages I-III } \\
\text { Stages IV }\end{array}$ & $\begin{array}{l}41(64.1 \%) \\
17(26.6 \%)\end{array}$ & $\begin{array}{l}17(37.8 \%) \\
23(51.1 \%)\end{array}$ & 0.005 \\
\hline $\begin{array}{l}\text { Treatment modalities } \\
\text { Surgery } \\
\text { RT or concurrent RT-CT } \\
\text { Surgery + RT or RT-CT }\end{array}$ & $\begin{array}{l}19(29.7 \%) \\
15(23.4 \%) \\
30(46.9 \%)\end{array}$ & $\begin{array}{l}3(6.7 \%) \\
11((24.4 \%) \\
31(57.4 \%)\end{array}$ & 0.010 \\
\hline $\begin{array}{l}\text { Role of RT } \\
\text { RT included in treatment }\end{array}$ & $45(70.3 \%)$ & $42(93.3 \%)$ & 0.002 \\
\hline $\begin{array}{l}\text { Therapy completed } \\
\text { Less than } 2 \text { years ago } \\
\text { Two years or more ago }\end{array}$ & $\begin{array}{l}15(23.4 \%) \\
49(76.6 \%)\end{array}$ & $\begin{array}{l}21(46.7 \%) \\
24(53.3 \%)\end{array}$ & 0.014 \\
\hline $\begin{array}{l}\text { Oral problems } \\
\text { Mucosa irritability } \\
\text { Mouth wide opening } \\
\text { Thick and sticky saliva } \\
\text { Problems with chewing }\end{array}$ & $\begin{array}{l}23(35.9 \%) \\
5(7.8 \%) \\
35(54.7 \%) \\
4(6.3 \%)\end{array}$ & $\begin{array}{l}28(62.2 \%) \\
15(33.3 \%) \\
38(84.4 \%) \\
16(35.6 \%)\end{array}$ & $\begin{array}{l}0.007 \\
0.001 \\
0.001 \\
0.000\end{array}$ \\
\hline $\begin{array}{l}\text { Problems with } \\
\text { Feeding } \\
\text { Feeding in the presence of family } \\
\text { Feeding in the public } \\
\text { Enjoying food }\end{array}$ & $\begin{array}{l}5(7.8 \%) \\
3(4.7 \%) \\
7(10.9 \%) \\
3(4.7 \%)\end{array}$ & $\begin{array}{l}35(77.8 \%) \\
28(62.2 \%) \\
36(80 \%) \\
17(37.7 \%)\end{array}$ & $\begin{array}{l}0.000 \\
0.000 \\
0.000 \\
0.000\end{array}$ \\
\hline Avoiding public areas & $18(28.1 \%)$ & $34(75.6 \%)$ & 0.020 \\
\hline $\begin{array}{l}\text { Loss of smell } \\
\text { Impaired taste } \\
\text { Acid reflux and heartburn }\end{array}$ & $\begin{array}{l}7(10.9 \%) \\
18(28.1 \%) \\
18(28.1 \%)\end{array}$ & $\begin{array}{l}15(33.3 \%) \\
34(75.6 \%) \\
22(48.9 \%)\end{array}$ & $\begin{array}{l}0.004 \\
0.000 \\
0.027\end{array}$ \\
\hline $\begin{array}{l}\text { Pain } \\
\text { Oral pain } \\
\text { Throat pain }\end{array}$ & $\begin{array}{l}4(6.3 \%) \\
12(18.8 \%)\end{array}$ & $\begin{array}{l}14(31.1 \%) \\
18(40 \%)\end{array}$ & $\begin{array}{l}0.001 \\
0.014\end{array}$ \\
\hline $\begin{array}{l}\text { Persistent coughing } \\
\text { History of recurrent pneumonia } \\
\text { Presence of hoarseness }\end{array}$ & $\begin{array}{l}30(46.9 \%) \\
2(3.1 \%) \\
25(39.1 \%)\end{array}$ & $\begin{array}{l}38(84.4 \%) \\
7(15.6 \%) \\
28(62.2 \%)\end{array}$ & $\begin{array}{l}0.000 \\
0.031 \\
0.017\end{array}$ \\
\hline $\begin{array}{l}\text { Loss of weight } \\
\text { Use of nutritional supplements }\end{array}$ & $\begin{array}{l}17(26.6 \%) \\
6(9.3 \%)\end{array}$ & $\begin{array}{l}24(53.3 \%) \\
16(35.6 \%)\end{array}$ & $\begin{array}{l}0.005 \\
0.001\end{array}$ \\
\hline
\end{tabular}

*The data on tumor stage was accessible only for 95 patients; CT = chemotherapy; RT = radiotherapy; $S D$ = standard deviation

After exclusion of all dysphagia-derived parameters (i.e. problems with feeding, avoiding public areas, enjoying food, loss of weight, use of nutritional supplements), the remaining, dysphagiagenerating variables that appeared statistically significant in univariate analysis were included into the multiple regression model for testing their impact to dysphagia formation. In the final model, only problems with persistent cough remained significant (coefficient 0.249: 95\% confidential interval $0.035-0.472 ; \mathrm{p}=0.023)$. 


\section{Discussion}

The management of locally advanced HNC still represents a challenge to the clinicians despite recent improvements in diagnostics and treatment. Excessive scarring secondary to aggressive surgery, intensive irradiation and systemic therapy may result in different degree of swallowing disorders. ${ }^{17,18}$ Malnutrition, the need for enteral tube feeding, social isolation and the feeling of hopelessness may significantly impair quality of patient's life. ${ }^{19,20}$ The results of our study confirmed these observations. Almost $40 \%$ of patients from the present study had problems with feeding out of their homes and almost half of the patients avoided going to public areas and thus had social life impaired. Majority of patients from the DG reported problems with feeding $(77.8 \%)$, feeding in public $(80 \%)$, and even feeding in the presence of the family $(62.2 \%)$. In the OTH patients, these problems were recorded significantly less often. Discomfort when eating in presence of other people was probably one of the important reasons that $75.6 \%$ of the patients who reported difficulties with swallowing also reported avoiding public places, which makes dysphagia an important reason for their social isolation.

The prevalence of dysphagia in our study was $41.3 \%$, which is less than in some other series. $3,4,6,7$ We assume that differences in studied populations of patients in regard to distribution of primary tumor sites and treatment modalities used as well as methods for dysphagia assessment are the reasons for this discrepancy.

As expected, among our patients a higher prevalence of dysphagia was significantly related to primaries originated in the swallowing-related areas of the head and neck and to more advanced disease stages, which is in line with other reports. ${ }^{7}$ In addition, radiation therapy also appeared to be a significant causative factor for dysphagia in univariate analysis. Among 45 patients with dysphagia, almost all $(93.3 \%)$ were treated with radiation therapy, either as the sole therapy or in combination with surgery and/or chemotherapy. One of the reasons for more aggressive treatment scenario could be more advanced tumor stage that necessitates addition of radiotherapy to surgery or intensification of radiotherapy with concurrent chemotherapy. However, using multiple regression analysis with disease stage taking into account, radiotherapy did not remain in the final model. This result supports the observation of other authors who found no differences in the severity of dysphagia or aspiration according to type of treatment.,
Pathophysiological mechanisms implicated in development of swallowing disorders after HNC treatment differ according to modality used. In case of surgery, tissue defect resulted from tumor removal adversely effects organ's function because its integrity is truncated. When organs crucial for swallowing are the site of primary tumor (e.g. tongue, velopharyngeal orifice, larynx, pharyngeal wall, and upper esophageal sphincter), dysphagia appears. With destruction of primary tumor, radiation therapy induces scarring at the site of its origin and fibrotic changes elsewhere in tissues inside irradiation field, which reduces their elasticity and flexibility. Thus, the dose-volume relationship in case of pharyngeal constrictor muscles appears to be the most important predictor of later swallowing disorders. ${ }^{21}$

Sensory impairment of the upper aerodigestive tract mucosa as a result of tissue loss or post-radiotherapy changes seems also to be an important causative mechanism of swallowing disorders and especially aspiration. Thus, both, surgical treatment and radiation therapy, can adversely influence laryngeal innervation and alter its functions, including its role in swallowing. In the present study, $62.2 \%$ of the patients with dysphagia reported hoarseness, and $84.4 \%$ of them reported persistent cough. In multiple regression modelling only persistent cough remained significant factor related to dysphagia. The cough can be a consequence of hyposensibility of the larynx after surgery or irradiation, leading to persistent micro aspiration in the trachea. When the secretions or food come in contact with intact tracheal mucosa with preserved sensibility, they induce protective coughing which successfully clears the airway. ${ }^{12,15}$ This cough can be the reason that in our series only $8.2 \%$ of the patients experienced pneumonia. The flexible endoscopic evaluation of swallowing could prove this hypothesis; however, no such examination was foreseen in the study protocol.

There are other symptoms which can cause dysphagia that appeared more often in the DG than in the OTH, i.e. oral pain $(31.1 \%$ vs. $6.3 \%)$, throat pain ( $40 \%$ vs. $18.8 \%)$, oral mucosa irritability $(62.2 \%$ vs. $35.9 \%)$, thick saliva $(84.4 \%$ vs. $54.7 \%)$, impaired sense of taste $(75.6 \%$ vs. $28.1 \%)$, change of smelling abilities (33.3\% vs. $10.9 \%)$. The highest prevalence was reported for problems related to production of saliva and to impaired tasting abilities, which can be interconnected. ${ }^{5}$ However, in our analysis, none of these parameters demonstrated to be significantly related to dysphagia in multiple regression testing. 
Dysphagia was repeatedly reported to be a chronic problem in HNC patients cured of their cancer. Nguyen et al. showed by means of repeated modified barium swallow that up to two years post-surgery dysphagia disappeared in $8 \%$ and decreased in its severity in $32 \%$ of the patients; in all others patients it worsened or remained unchanged. ${ }^{15}$ This observation confirms our finding that dysphagia was more often reported in patients with a less than 2 years of follow-up after treatment.

Other late sequel in patients treated for HNC is changed quality of mucus in the upper aerodigestive tract. Among our DG patients, thick and sticky mucus was reported in $84.4 \%$ of cases. We hypothesize that alterations in mucus quality are responsible for improper dissolution of taste molecules, which resulted in impaired sense of taste. The other cause of (partial) taste loss are postirradiation changes of the taste buds in oral cavity and oropharynx or loss of receptors because of surgical excision. ${ }^{22}$ However, a well-known interconnection between the sense of taste and the sense of smell could participate to decreased smelling ability which was reported in one third of our patients with dysphagia. ${ }^{23}$

An interesting finding of the present study is a connection between dysphagia and the symptoms of gastroesophageal reflux. Reflux of gastric acid and pepsin is well-recognized etiologic factor in dysphagia even in subjects without cancer, simply by causing inflammation of the laryngeal and hypopharyngeal mucosa. ${ }^{24,25}$ Such inflammation can additionally aggravate pre-existing radiomucositis in irradiated patients, leading to scarring and impaired sensitivity of involved mucosa. Reflux to the level above the upper esophageal sphincter was found to impair the sensibility of the throat and hypopharynx in otherwise healthy subjects. ${ }^{26}$

The only significant variable in multiple regression analysis was persistent cough. The gastroesophageal reflux to the level of laryngopharynx can also be the reason for persistent cough, induced by altered mucosal sensitivity and mobility impairment of the cilia of respiratory epithelium of the larynx. ${ }^{27}$ Consequently, mucus accumulated at the laryngeal inlet causes throat clearing and persistent cough. The causative role of microaspiration and impaired mucosal sensitivity in persistent cough has already been mentioned.

The third association between the gastroesophageal reflux and persistent cough is managed through the neural reflexes. The vagus nervemediated reflex arc originates at distal esophagus and can initiate a reflex coughing when the receptors in the esophageal wall are stimulated by the reflux..$^{28,29}$ Therefore, in order to decrease the incidence of coughing in the patients after HNC treatment, pre-treatment identification and proper management of patients with gastroesophageal reflux symptoms is mandatory.

We acknowledge the limitations of our study. This is a questionnaire-based review of a small number of patients who might be too subjective in their answers. There is also a heterogeneity of population regarding the cancer location, stage of the disease, and treatment modalities used. The exact data from the medical documentation regarding anatomical details of cancer extension, treatment intensity and its complications and assessment of dysphagia with objective methods would add significantly to the quality of study.

In conclusion, in order to enable safe swallowing and to reduce the risk of aspiration in HNC patients, a systematic assessment and rehabilitation of swallowing should be organized before and after treatment. According to presented results, special emphasis should be put on gastroesophageal reflux screening and treatment before, during and after the therapy. Only with implementation of these interventions in the routine management algorithms used in HNC patients, a quality of life improvement can be expected.

\section{References}

1. Epidemiology and Cancer Registry, Cancer Registry of Republic of Slovenia, Institute of Oncology Ljubljana. Cancer in Slovenia 2015. Ljubljana: Institute of Oncology Ljubljana; 2018.

2. van der Molen L, van Rossum MA, Burkhead LM, Smeele LE, Hilgers FJM. Functional outcomes and rehabilitation strategies in patients treated with chemoradiotherapy for advanced head and neck cancer: a systematic review. Eur Arch Otorhinolaryngol 2009; 266: 889-900. doi: 10.1007/ s00405-008-0817-3

3. Hey C, Lange BP, Aere C, Zaretsky Y, Sader R, Stőver T, et al. Predictability of oral and laryngopharyngeal function for aspiration and limitation of oral intake in patients after surgery for head and neck cancer. Anticancer Res 2013; 33: 3347-53. PMID: 23898102

4. Rinkel RN, Verdonck-Leeuw IM, van den Brakel N, de Bree R, Eerenstein SE, Aaronson N, et al. Patient-reported symptom questionnaires in laryngeal cancer: voice, speech and swallowing. Oral Oncol 2014; 50: 759-64. doi: 10.1016/j.oraloncology.2014.05.009

5. Likhterov I, Ru M, Ganz C, Urken ML, Chai R, Okay D, et al. Objective and subjective hyposalivation after treatment for head and neck cancer: longterm outcomes. Laryngoscope 2018; 128: 2732-9. doi: 10.1002/lary.27224

6. Patterson JM, McColl E, Carding PN, Wilson JA. Swallowing beyond six years post (chemo)radiotherapy for head and neck cancer; a cohort study. Oral Oncol 2018; 83: 53-8. doi: 10.1016/j.oraloncology.2018.06.003

7. Strojan P, Hutcheson KA, Eisbruch A, Beitler JJ, Langendijk JA, Lee AWM, et al. Treatment of late sequelae after radiotherapy for head and neck cancer Cancer Treat Rev 2017; 59: 79-92. doi: 10.1016/j.ctrv.2017.07.003 
8. Carmignani I, Locatello G, Desideri I, Bonomo P, Olmetto E, Livi L, et al Analysis of dysphagia in advanced-stage head-and-neck cancer patients: impact on quality of life and development of a preventive swallowing treatment. Eur Arch Otorhinolaryngol 2018; 275: 2159-67. doi: 10.1007/ s00405-018-5054-9

9. Nguyen NP, Frank C, Moltz CC, Vos P, Smith HJ, Karlsson U, et al. Impact of dysphagia on quality of life after treatment of head and neck cancer. Int $J$ Radiat Oncol Biol Phys 2005; 61: 772-8. doi: 10.1016/j.jjrobp.2004.06.017

10. Eisele DW, Koch DG, Tarazi AE, Jones B. Case report: aspiration from delayed radiation fibrosis of the neck. Dysphagia 1991; 6: 120-2. PMID: 1935259

11. Smith RV, Kotz T, Beitler JJ, Wadler S. Long-term swallowing problems after organ preservation therapy with concomitant radiation therapy and intravenous hydroxyurea. Arch Otolaryngol Head Neck Surg 2000; 126: 384-9. doi: 10.1001/archotol.126.3.384

12. Eisbruch A, Lyden T, Bradford CR, Dawson LA, Haxer MJ, Miller AE, et al. Objective assessment of swallowing dysfunction and aspiration after radiation concurrent with chemotherapy for head and neck cancer. Int $J$ Rad Oncol Biol Phys 2002; 53: 23-8. doi: 10.1016/S0360-3016(02)02712-8

13. Ward EC, Bishop B, Frisby J, Stevens RM. Swallowing outcomes following laryngectomy and pharyngolaryngectomy. Arch Otolaryngol Head Neck Surg 2002; 128: 181-6. doi: 10.1001/archotol.128.2.181

14. Pauloski BR, Rademaker AW, Logemann JA, Colangelo LA. Speech and swallowing in irradiated and nonirradiated postsurgical oral cancer patients. Otolaryngol Head Neck Surg 1998; 118: 616-24. doi: $10.1177 / 019459989811800509$

15. Nguyen NP, Moltz CC, Frank C, Vos P, Smith HJ, Karlsson U, et al. Evolution of chronic dysphagia following treatment for head and neck cancer. Oral Oncol 2006; 42: 374-80. doi: 10.1016/j.oraloncology.2005.09.003

16. Singer S, Arraras JI, Chie WC, Fisher SE, Galalae R, Hammerlid E, et al. Performance of the EORTC questionnaire for the assessment of quality of life in head and neck cancer patients EORTC QLQ-H\&N35: a methodological review. Qual Life Res 2013; 22: 1927-41. doi: 10.1007/s11136-012-0325-1

17. Nguyen NP, Moltz CC, Frank C, Vos P, Smith HJ, Karlsson U, et al. Long-term aspiration following treatment for head and neck cancer. Oncology 2008; 74: 25-30. doi: 10.1159/000138976

18. Nguyen NP, Sallah S. Combined chemotherapy and radiation in the treatment of locally advanced head and neck cancers. In Vivo 2000; 14: 35-9. PMID: 10757059

19. Al-Sarraf M. Treatment of locally advanced head and neck cancer, historical and critical review. Cancer Control 2002; 9: 387-99. doi: $10.1177 / 107327480200900504$

20. Lazarus CL, Husaini H, Hu K, Culliney B, Li Z, Urken M, et al. Functional outcome and quality of life after chemoradiotherapy: baseline and 3 and 6 months' post-treatment. Dysphagia 2014; 29: 365-75. doi: 10.1007/ s00455-014-9519-8

21. Duperz F, Madani I, De Potter B, Botenberg T, De Neve W. Systematic review of dose-volume correlates for structures related to late swallowing disturbances after radiotherapy for head and neck cancer. Dysphagia 2013; 28 337-49. doi: 10.1007/s00455-013-9452-2

22. Maes A, Huygh I, Weltens C, Vandevelde G, Delaere P, Evers G, et al. De Gustibus: time scale of loss and recovery of tastes caused by radiotherapy. Radiother Oncol 2002; 63: 195-201. doi: 10.1016/S0167-8140(02)00025-7

23. Czarnecki L, Fontanini A. Gustation and olfaction: the importance of place and time. Curr Biol 2019; 29: R18-20. doi: 10.1016/j.cub.2018.11.038

24. Bulmer DM, Ali MS, Brownlee IA, Dettmar PW, Pearson JP. Laryngeal mucosa: its susceptibility to damage by acid and pepsin. Laryngoscope 2010 120: 777-82. doi: 10.1002/lary.20665

25. Johnston N, Wells CW, Samuels TL, Blumin JH. Pepsin in nonacidic refluxate can damage hypopharyngeal epithelial cells. Ann Otol Rhinol Laryngol 2009; 118: 677-85. doi: 10.1177/000348940911800913

26. Phua SY, McGarvey L, Ngu M, Ing A. The differential effect of gastroesophageal reflux disease on mechanostimulation and chemostimulation of the laryngopharynx. Chest 2010; 138: 1180-5. doi: 10.1378/chest.09-2387

27. Hawkshaw M, Pebdani P, Sataloff RT. Reflux laryngitis: an update, 20092012. J Voice 2013; 27: 486-494. doi: 10.1016/j.jvoice.2013.03.001
28. Johnston N, Bulmer D, Gill GA, Panetti M, Ross PE, Pearson JP, et all. Cell biology of laryngeal defenses in health and disease: further studies. Ann Otol Rhinol Laryngol 2003; 112: 481-91. doi: 10.1177/000348940311200601

29. Pauwels A, Blondeau K, Dupont L, Sifrim D. Cough and gastroesophageal reflux: from the gastroenterologist end. Pulm Pharmacol Ther 2009; 22 135-8. doi: 10.1016/j.pupt.2008.11.007 